\title{
Multiple effects of CD40-CD40L axis in immunity against infection and cancer
}

This article was published in the following Dove Press journal: ImmunoTargets and Therapy

\author{
Anjuman Ara ${ }^{1,2}$ \\ Khawaja Ashfaque Ahmed ${ }^{1,2}$ \\ Jim Xiang ${ }^{1,2}$ \\ 'Cancer Research Cluster, \\ Saskatchewan Cancer Agency, \\ Saskatoon, Saskatchewan, Canada; \\ ${ }^{2}$ Division of Oncology, College of \\ Medicine, University of Saskatchewan, \\ Saskatoon, Saskatchewan, Canada
}

Correspondence: Jim Xiang

Cancer Research Cluster, Room 4D30.I, Saskatchewan Cancer Agency, 107 Wiggins Road, Saskatoon, SK S7N 5E5, Canada

Tel +I 3069667039

Fax +I 3069667047

Email jim.xiang@usask.ca

\begin{abstract}
CD}^{+}$cytotoxic $\mathrm{T}$ lymphocyte $(\mathrm{CTL})$ protects against infection and cancer cells. Understanding the mechanisms involved in generation and maintenance of effective CTL responses is essential for improving disease therapy and vaccine protocols. During CTL responses, immune cells encounter several tightly regulated signaling pathways; therefore, in such a dynamic process, proper integration of critical signals is necessary to orchestrate an effective immune response. In this review, we have focused on CD40-CD40L interactions (a key signal) in the regulation of dendritic cell (DC)- $\mathrm{T}$ cell $\left(\mathrm{CD} 4^{+} \mathrm{T}\right.$ and $\left.\mathrm{CD} 8^{+} \mathrm{T}\right)$ cross-talk, rescuing CTL exhaustion, and converting DC tolerization. We have also highlighted the knowledge gap and future directions to design immunotherapies.
\end{abstract}

Keywords: CD40-CD40L, costimulatory signals, T-cell immunity, CTL exhaustion, mTORC1, trogocytosis

\section{Introduction}

$\mathrm{CD}^{+}$cytotoxic $\mathrm{T}$ lymphocyte (CTL) responses play a critical role in immunity against infection and cancer. ${ }^{1}$ Three key molecular signals are required to generate effective CTL responses. Signal 1 is delivered when antigen-specific T-cell receptor (TCR) binds to peptide-loaded major histocompatibility complex (MHC) on antigen-presenting cells (APCs) and signal 2 is generated through the engagement of costimulatory molecules, namely B7-1 (CD80)/B7-2 (CD86) and CD28 (e.g., T-cell CD28/APC CD80). ${ }^{1}$ Consequent to Ag-specific T cell-APC interactions, an immunologic synapse is formed comprising a central cluster of TCR-MHC-peptide complexes and CD28-CD80 interactions surrounded by rings of engaged accessory molecules (e.g., complexed LFA-1-CD54). ${ }^{1-3}$ The third signal is the secretion of cytokines, which further enhance, modify, and skew the responding effector CTLs. ${ }^{4,5}$ If signal 1 is generated in the absence of signal 2, then it renders tolerance instead of immunity. ${ }^{6}$ Thus, costimulation or efficient engagement of different surface molecules on APCs and T cells is important to trigger efficient immune responses.

Costimulatory molecules are generally divided into two groups: the CD28/B7 family group and tumor necrosis factor (TNF)/tumor necrosis factor receptor (TNFR) family group. CD28 is a T-cell surface receptor that binds to costimulatory molecules B7-1 (CD80) and B7-2 (CD86) on APCs such as dendritic cells (DCs) and macrophages, and is involved in triggering of cell-mediated immune responses. ${ }^{7}$ The inhibitory molecule of the CD28 family is cytotoxic T lymphocyte antigen 4 (CTLA-4). CD28 and CTLA-4 are two receptors that recognize the same ligands (B7 molecules) but have opposite functional effects on T-cell activation. ${ }^{8}$ CD40 is a member of TNFR family, which 
includes OX40 (CD134), 4-1BB (CD137), and CD27. ${ }^{9}$ OX40 is expressed on activated $\mathrm{T}$ cells, whereas its ligand partner OX40L is located on APCs. ${ }^{10} 4-1 \mathrm{BB}$ (CD137) is expressed on $\mathrm{B}$ cells, macrophages, and DCs, whereas its ligand 4-1BBL is expressed on DCs and macrophages. ${ }^{11}$ The ligand for CD27, CD70, is also found on APCs. ${ }^{12}$ TNF/TNFR family members are induced in hours to days following the TCR engagement and involve later stages of T-cell activation. ${ }^{13}$ In this review, we focus on CD40-CD40L engagement in licensing DCs, promoting T-cell memory and converting CTL exhaustion in chronic infection.

CD40 receptor and its ligand CD40L (CD154) belong to the TNF:TNFR family. CD40 was originally identified as a surface marker on bladder carcinoma cells and B cells. ${ }^{14}$ Later, CD40 has been found to express on B cells, macrophages and DCs, as well as many nonimmune cells. CD40CD40L signaling in B cells is important for generation of long-lived plasma cells and memory B cells as well as for their survival. Here, we focus on the role of CD40-CD40L signaling in T-cell immunity. The $\mathrm{CD} 40 \mathrm{~L}$ is a natural ligand for CD40 and a Type II, 39-kDa membrane glycoprotein. Following CD40-CD40L interaction on the cell surface; intracellular signaling is facilitated by recruitment of TNFRassociated factors (TRAFs) in the inner membrane of cells, which leads to the activation of different pathways, such as the canonical and noncanonical nuclear factor $\mathrm{\kappa B}$ pathway, mitogen-activated protein kinases, phosphatidylinositol-3 kinase (PI3K), and the phospholipase $\mathrm{C} \gamma$ pathway. ${ }^{15} \mathrm{CD} 40$ $\mathrm{CD} 40 \mathrm{~L}$ is a pair of costimulatory molecules, and their interaction is necessary for successful adaptive immune responses. There is a plethora of reports that suggest the importance of CD40-CD40L interaction in immune responses mainly in the development of CD8 ${ }^{+}$CTLs. Two models have been proposed by different labs regarding CD40 signaling in CTL responses. ${ }^{16}$ The first model suggests that stimuli from CD40L of $\mathrm{CD}^{+} \mathrm{T}$ helper (Th) cells to CD40-expressing DCs are essential for DC maturation (licensing), and in turn, licensed DCs can trigger effective CTL responses. ${ }^{16}$ However, the requirement for CD40 in DC licensing can be bypassed by inflammatory responses to pathogens that activate APCs directly. ${ }^{17}$ The second model suggests that CD40L-expressing $\mathrm{CD} 4^{+} \mathrm{T}$ cells activate $\mathrm{CD} 40$-expressing $\mathrm{CD} 8^{+} \mathrm{T}$ cells directly, ${ }^{18}$ predicting that $\mathrm{CTL}$ responses to all antigens require $\mathrm{CD} 40$ signaling on $\mathrm{CD} 8^{+} \mathrm{T}$ cells. Altogether, the important roles for $\mathrm{CD} 40-\mathrm{CD} 40 \mathrm{~L}$ interaction give rise to many immune events, which is very important for the host defense against pathogens and cancer.

\section{CD40 signaling on DCs for DC licensing}

Immune responses to helper T-cell-dependent antigens require $\mathrm{CD} 4^{+} \mathrm{T}$-cell help. ${ }^{19} \mathrm{DCs}$ cannot prime naïve $\mathrm{CD} 8^{+} \mathrm{T}$ cells in MHC II knockout mice (CD4 ${ }^{+} \mathrm{T}$ deficient). It was shown that $\mathrm{CD}^{+} \mathrm{T}$ cells provide help by engaging their CD40L ${ }^{20}$ with CD40 on DCs and license DCs to make them a powerful stimulator of immune response. ${ }^{19,21,22}$ Later, it was suggested that licensed DCs mediate $\mathrm{CD} 8^{+} \mathrm{T}$-cell responses by enhancing B7 molecules expression and secretion of cytokines such as interleukin 12 (IL-12) that promotes T-cell differentiation..$^{21}$ Moreover, CD40-CD40L interaction also causes an increased expression of MHC, costimulatory, and adhesion molecules and results in an enhanced induction of proinflammatory chemokines and cytokines in DCs. ${ }^{23}$ Thus, activation of DCs through CD40-CD40L signal provides the "CD4+ $\mathrm{T}$ cell help" necessary for empowering DCs to cross-prime naïve T cells. ${ }^{24}$ But the conundrum was how these three cell types, which are rare and migratory, present in the same location to interact with each other. Moreover, there are several reports that provided incongruous results that $\mathrm{CD} 4^{+} \mathrm{T}$ cells can activate APCs through a CD40-independent pathway. ${ }^{25,26}$ However, it was suggested that when DCs are activated by cognate $\mathrm{CD} 4^{+} \mathrm{T}$ cells, DCs start secreting chemokines CCL3 and CCL4. ${ }^{27}$ Chemokines guide cognate interaction of CCR5-expressing CD8 $8^{+} \mathrm{T}$ cells with licensed DCs, leading to triggering strong CTL responses through three-cell interactions. ${ }^{27}$ Our lab previously provided in vivo evidence for a dynamic three-cell interaction model for CTL responses, wherein once $\mathrm{DCs}$ are licensed by $\mathrm{DC}-\mathrm{CD} 4^{+} \mathrm{T}-$ cell interactions, licensed DCs do not require the simultaneous presence of cognate $\mathrm{CD} 4^{+} \mathrm{T}$ cells, ${ }^{16}$ which is in contrast to the previous study suggesting absolute requirement of $\mathrm{DC}-\mathrm{CD} 4^{+}$ $\mathrm{T}-\mathrm{CD} 8^{+} \mathrm{T}$ ternary clusters for CTL responses. ${ }^{18}$ However, it was not determined if CD40-CD40L interaction induces DCs to secrete CCL3 and CCL4 chemokines. Furthermore, it was not known if DCs licensed through CD40-CD40L interaction requires CCR5 expression by $\mathrm{CD} 8^{+} \mathrm{T}$ cells to induce CTL responses.

\section{CD40 signaling on $\mathrm{CD}^{+} \mathrm{T}$ cells for $\mathrm{T}$-cell memory}

CD40 is expressed not only on APCs such as B cells and DCs, but also on activated CD8 ${ }^{+} \mathrm{T}$ cells. ${ }^{23}$ However, it was not clear which cellular population plays a critical role in delivering CD40 signaling for CTL responses. Bourgeois et al have demonstrated that generation of memory CD $8^{+}$ $\mathrm{T}$ cells involves expression of CD40 on $\mathrm{CD} 8^{+} \mathrm{T}$ cells, but 
requires $\mathrm{CD}^{+} \mathrm{T}$-cell help through $\mathrm{CD} 40-\mathrm{CD} 40 \mathrm{~L}$ interaction for forming $\mathrm{DC}-\mathrm{CD} 4^{+} \mathrm{T}-\mathrm{CD} 8^{+} \mathrm{T}$ ternary cluster. ${ }^{18}$ Authors further suggested that such CD4-CD8 T-cell interaction for CD40-CD40L signaling absolutely required DCs and three-cell interactions, but activation of $\mathrm{CD}^{+} \mathrm{T}$ cells was independent of CD40 expression by DCs. ${ }^{18}$ In an infectious disease model, a previous study reported CD40L expression on DCs, and suggested that CD40L-expressing DCs could deliver CD40-CD40L signaling onto $\mathrm{CD}^{+} \mathrm{T}$ cells for induction of CTL responses without requiring $\mathrm{CD}^{+}$ T cells. ${ }^{28}$ Intercellular trogocytosis (a new phenomenon in cellular immunology) that is the exchange of membrane molecules between immune cells such as DCs and T cells through 1) internalization and recycling of molecules in synapse formed between DCs and T cells, 2) dissociationassociated process, 3 ) absorption of DC-released exosomes (EXOs) by T cells, and 4) uptake of DC membrane nanotube by $\mathrm{T}$ cells has been found to play an important role in modulation of immune responses (Figure 1). ${ }^{29}$ Previously, we proposed a dynamic two-cell interaction model for induction of CTL responses. ${ }^{30}$ According to this proposed model, $\mathrm{CD}^{+}$helper T cells when activated by DCs acquire not only the synapse-composed MHC class II and costimulatory molecules (CD54 and CD80), but also the bystander pMHC-I from APCs through a process called internalization and recycling of molecules in synapse formed between DCs and T cells (Figure 1), ${ }^{31}$ and become CD4 ${ }^{+}$T-helper APCs (Th-APCs) that can directly stimulate CD8 ${ }^{+}$CTL proliferation and memory formation (Figure 1). ${ }^{2,3}$ We demonstrated that Th-APCs can also form through DC-released EXO uptake (Figure 1). ${ }^{32,33}$ We showed that nonspecific $\mathrm{CD}^{+} \mathrm{T}$ cells can uptake antigen-specific DC-released EXOs and are able to stimulate antigen-specific $\mathrm{CD} 8^{+} \mathrm{CTL}$ responses and long-term T-cell memory. ${ }^{32}$ Later, our lab provided in vivo evidence for the direct $\mathrm{CD} 4^{+} \mathrm{T}$-cell- $\mathrm{CD} 8^{+} \mathrm{T}$-cell interactions and demonstrated that such interactions do not require the simultaneous presence of DCs. ${ }^{16}$ Using two-photon imaging, we further provided definite evidence that pMHC-I-acquired $\mathrm{CD}^{+} \mathrm{T}$ cells can directly interact with $\mathrm{CD} 8^{+} \mathrm{T}$ cells for delivering CD40L signal in vivo. ${ }^{16} \mathrm{~A}$ recent study from another group also provided two-photon imaging data that strongly supported our finding of direct $\mathrm{CD} 4^{+} \mathrm{T}$-cell-CD8 ${ }^{+} \mathrm{T}$-cell

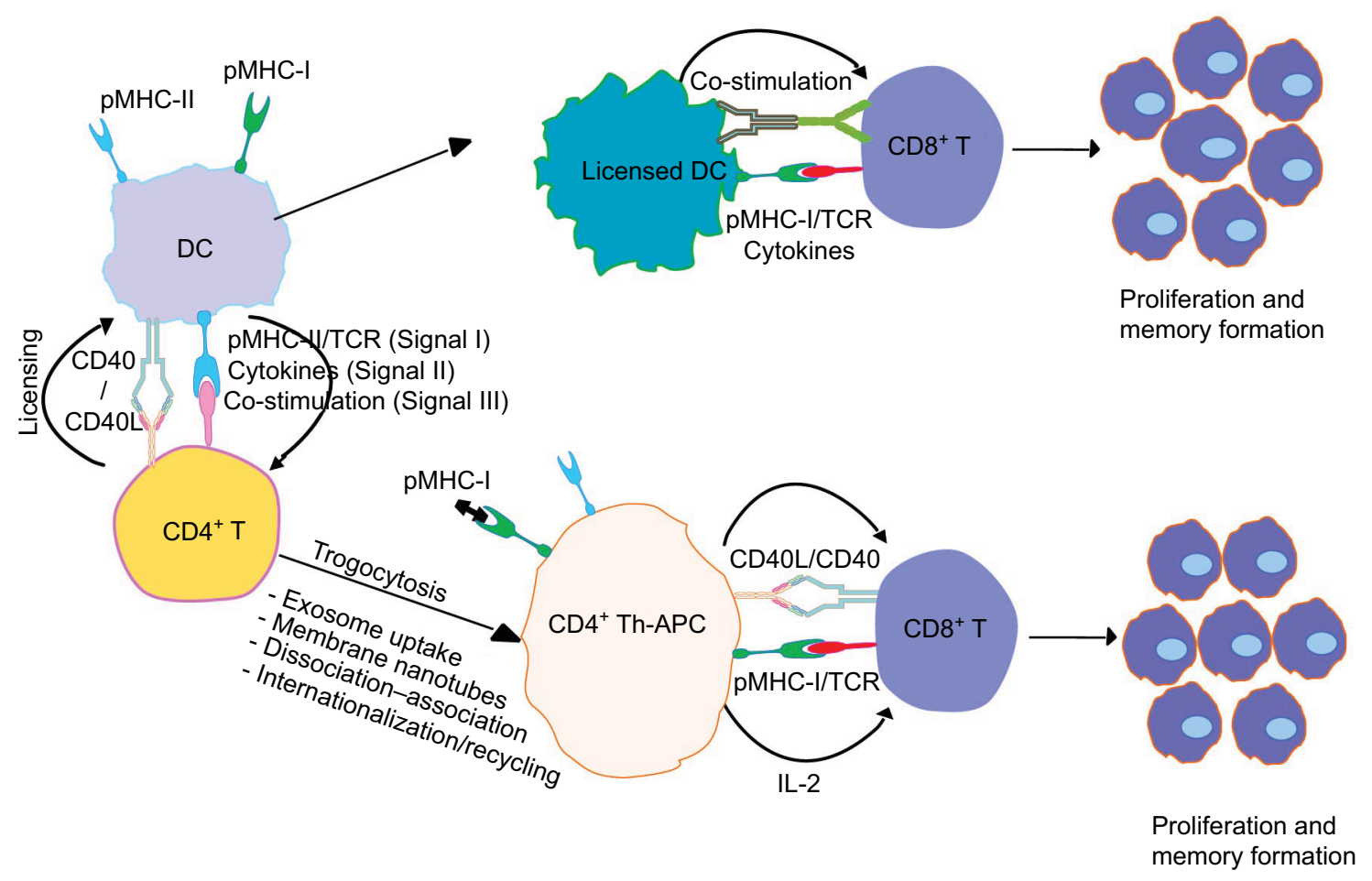

Figure I CD40-CD40L interactions at DC-T cell and T cell-T cell interface.

Notes: The cross-priming DC first interacts with the antigen-specific CD4 ${ }^{+} \mathrm{T}$ for the crucial first step in CD40-CD40L-dependent CTL responses through PMHC-II

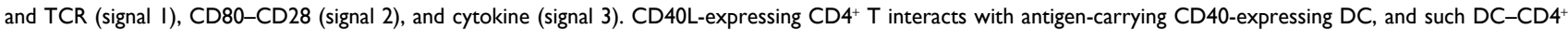
$\mathrm{T}$ interactions result in DC licensing and CD4 $4^{+} \mathrm{T}$-cell activation (priming). Cognate $\mathrm{CD} 8^{+} \mathrm{CTLs}$ can then receive helper or stimulatory signals, not only from $\mathrm{DC}-\mathrm{CD} 4^{+}$ $\mathrm{T}$ clusters but also separately from fully licensed $\mathrm{DCs}$ and $\mathrm{CD} 4^{+} \mathrm{T}$ cells, even after their dissociation from $\mathrm{DC}-\mathrm{CD} 4^{+} \mathrm{T}$ clusters. CD4 $4^{+}$helper $\mathrm{T}$ cells when activated by DCs acquire not only the synapse-composed MHC class II and costimulatory molecules (CD54 and CD80), but also the bystander PMHC-I from DC through trogocytosis (internalization, dissociation-association, exosomes uptake, or membrane nanotubes) and become CD4 $4^{+}$Th-APCs, resulting in direct CD4 ${ }^{+} \mathrm{T}-\mathrm{CD} 8^{+} \mathrm{T}$-cell interactions and subsequently delivery of CD40L signaling to CD40-expressing CD8 ${ }^{+} \mathrm{T}$ cells.

Abbreviations: APC, antigen-presenting cell; CTL, cytotoxic T lymphocyte; DC, dendritic cell; IL-2, interleukin 2; pMHC, peptide major histocompatibility complex; TCR, T-cell receptor; Th-APCs, T-helper APCs. 
interactions. ${ }^{34}$ In an infection model, Johnson et al showed that murine splenic DCs expressed CD40L after the viral infection or Toll-like receptor stimulation, which triggered CTL responses through signaling CD40 on $\mathrm{CD}^{+} \mathrm{T}$ cells. ${ }^{28}$ Our study previously demonstrated that CD40L on $\mathrm{CD}^{+} \mathrm{T}$ cells is crucial for a direct CD40 signaling on $\mathrm{CD}^{+} \mathrm{T}$ cells leading to an effective CTL response in noninflammatory conditions. ${ }^{16}$ We further reported that pMHC-I complexesacquired $\mathrm{CD}^{+}$Th-APCs through their endogenous IL-2 and CD40L signaling enhance survival of transferred CTLs and their differentiation into functional memory CTLs capable of protecting against highly metastasizing tumor challenge. ${ }^{35}$ These findings ${ }^{16,21,28,33}$ strongly suggest that CD40-CD40L signaling is critical for an effective CTL response, and that the consequences of CD40 signaling are complicated and depend on the type of cells expressing CD40 and the milieu in which the CD40 signal is provided.

\section{Counteraction of DC tolerization by CD40 signaling}

Subsets of DCs that present signal 1 (e.g., antigen peptideMHC complex) but not signal 2 (costimulatory signal) are defined as "immature" or "tolerogenic" DCs that can induce development of $\mathrm{CD}^{+}$or $\mathrm{CD}^{+}$regulatory $\mathrm{T}$ cells and anergy of antigen-specific T cells. ${ }^{36} \mathrm{CD} 40$ ligation has been used to boost $\mathrm{CD} 8^{+} \mathrm{T}$-cell responses to tumors and to break the peripheral self-tolerance. ${ }^{37}$ Brossart et al reported generation of CD83-positive mature DCs, induction of nuclear-localized RelB, and inhibition of IL-10R upregulation through the soluble CD40L signaling, ${ }^{38}$ indicating that CD40 ligation can antagonize IL-10-mediated inhibition on DC function. Later, Gurung et al reported that injection of the CD40L-negative naïve apoptotic $\mathrm{T}$ cells, but not the activated apoptotic $\mathrm{CD}^{+} \mathrm{T}$ cells expressing CD40L induced immune tolerance, and also demonstrated that co-injection of an agonistic anti-CD40 Ab with naïve apoptotic $\mathrm{T}$ cells induced robust immunity. ${ }^{39}$ Higham et al reported that local delivery of tumor-reactive $\mathrm{CD}^{+} \mathrm{T}$ cells engineered to express CD40L converted tolerogenic DCs in the prostate-draining lymph nodes. ${ }^{40}$ These findings indicate that T-cell CD40L signal can convert DC tolerance. Our lab previously demonstrated that tolerogenic $\mathrm{CD}^{-} 8^{-}$splenic DCs were capable of stimulating suppressive type $1 \mathrm{CD}^{+}$regulatory $\mathrm{T}$ cell responses through transforming growth factor beta secretion. ${ }^{41}$ Recently, we have found that anti-CD40 antibody-treated $\mathrm{CD}^{-} 8^{-} \mathrm{DCs}$ expressed a higher amount of I-A ${ }^{\mathrm{b}}, \mathrm{CD} 54, \mathrm{CD} 40, \mathrm{CD} 80$, and CD86, and were capable of stimulating $\mathrm{CD} 4^{+} \mathrm{Th} 1$ and $\mathrm{CD} 8^{+}$
CTL responses leading to induction of antitumor immunity, indicating that CD40 ligation efficiently converts tolerogenic CD4 ${ }^{-} 8^{-}$DCs into immunogenic ones. ${ }^{42}$ These data highlight the importance of CD40 signaling in addressing the issue of tolerogenic DCs.

\section{Conversion of $\mathrm{CD}^{+} \mathrm{CTL}$ exhaustion by CD40 signaling}

T-cell exhaustion is one of the major issues leading to ineffective virus control in human immunodeficiency patients. ${ }^{43}$ $\mathrm{CD}^{+}$CTL exhaustion mediated by a programmed cell death ligand-1 (PD-L1) pathway occurs in several chronic infections resulting in ineffective virus elimination. ${ }^{44}$ Programmed cell death protein-1 (PD-1) blockade has been found to restore the function of exhausted $\mathrm{CD} 8^{+} \mathrm{T}$ cells during chronic infection. ${ }^{43}$ The importance of CD40L-induced signaling in the context of PD-1 blockade for rescuing CTL exhaustion was previously proposed by Bhadra et al in a Toxoplasma model. ${ }^{45}$ Authors reported that blockade of CD40-CD40L pathway abrogated the ameliorative effects of anti-PD-L1 treatment on exhausted CD8 ${ }^{+} \mathrm{T}$ cells and identified CD40 as one of the molecules among a panel of costimulatory molecules, which was highly upregulated on $\mathrm{CD}^{+} \mathrm{T}$ cells in chronically infected mice. ${ }^{45}$ Isogawa et al also found that CD40-mediated activation of myeloid DCs could rescue CTL exhaustion of PD-1-inhibited $\mathrm{CD}^{+} \mathrm{T}$ cells. ${ }^{46}$ We previously generated novel OVA-specific EXO-targeted T-cell-based vaccine (OVA-Texo) expressing CD40L, and demonstrated that OVA-Texo vaccine stimulated potent CTL responses and T-cell memory. ${ }^{47}$ We earlier developed a mouse chronic infection model by infection of mice with OVA-expressing adenovirus, in which OVA-specific CTLs expressed PD-1 and lymphocyte-activation gene-3 (LAG-3) that were functionally exhausted. ${ }^{48}$ We further demonstrated that OVA-Texo vaccine could convert CTL exhaustion through CD40L signaling through activation of the $\mathrm{PI} 3 \mathrm{~K} / \mathrm{Akt} / \mathrm{mTORC} 1$ pathway. ${ }^{48}$ We have recently shown in our chronic infection model that agonist CD40 antibody-mediated CD40L signaling also synergizes with the PD-1 blockade in rescuing exhausted CTLs. ${ }^{49}$ These studies clearly indicate that CD40 signaling is very important for conversion of CTL exhaustion in chronic infection.

\section{Perspective}

It is widely accepted that costimulatory molecules play a crucial role in immunity and autoimmunity. Among the several costimulatory molecules, CD40, a potent stimulator 


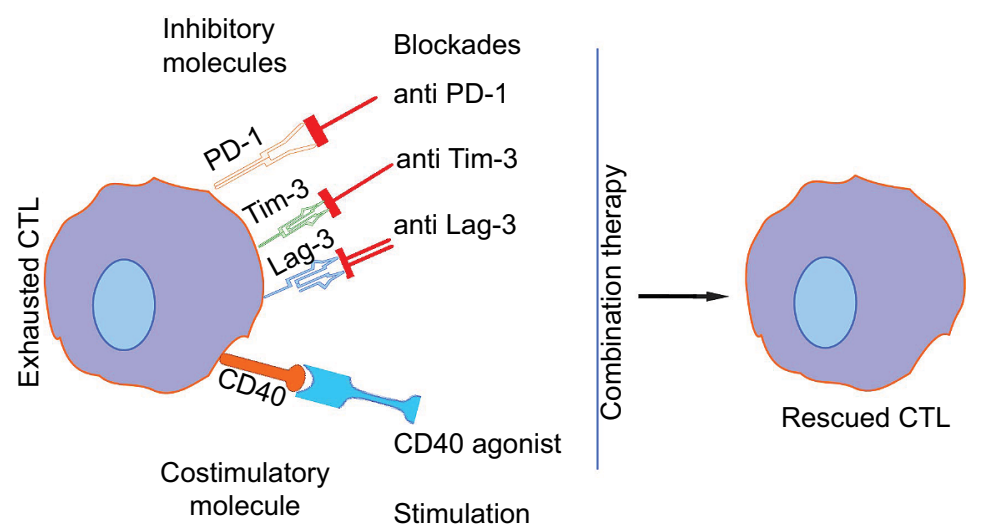

Figure 2 Combination therapy for rescuing CTL exhaustion.

Notes: Conversion of CTL exhaustion by a combinational treatment with antagonists for different inhibitory molecules such as PD-I, LAG-3, and Tim-3 to block and CD40 agonist for stimulation.

Abbreviations: CTL, cytotoxic T lymphocyte; LAG-3, lymphocyte-activation gene-3; PD-I, programmed cell death protein-I; Tim-3, T cell Ig-3.

of the immune system, has been extensively studied for its contribution to orchestration of protective immunity. When CD40 binds with CD40L, it recruits TRAF1 to TRAF6 to its cytoplasmic domains, and TRAF6 appears to be predominant in driving CD40-mediated signaling. ${ }^{21}$ An essential role for CD40-CD40L signaling on CD8 ${ }^{+} \mathrm{T}$ cells in memory CTL development is well established. Recent advances in immunology suggest that metabolic pathways play critical roles in controlling T-cell immunity. ${ }^{50}$ It was previously demonstrated that effector $\mathrm{T}$ cells require glycolysis to proliferate, whereas memory $\mathrm{T}$ cells depend on fatty acid metabolism for the long-term survival. Given that TRAF6 deficiency in CD8 ${ }^{+}$ $\mathrm{T}$ cells renders them defective in fatty acid metabolism ${ }^{51}$ and that TRAF6 is a critical molecule in CD40-induced downstream signaling pathways, ${ }^{21}$ it will be interesting to investigate the role for CD40 signaling in switching effector T-cell metabolism from glycolysis to fatty acid oxidation for developing memory $\mathrm{T}$ cells. In chronic infection, exhausted CTLs expressed not only PD- $1,{ }^{43}$ but also other inhibitory receptors such as LAG-3, T-cell Ig-3 (Tim-3), and TIGIT. ${ }^{52}$ An enhanced effect on conversion of CTL exhaustion by a combinational treatment with antagonists (blockades for blocking inhibition) for different inhibitory molecules such as PD-1, LAG-3, and Tim-3 has been shown. ${ }^{53}$ Our studies $^{49}$ and those of others ${ }^{45,46}$ also demonstrated that CD40 signaling (costimulatory molecule for stimulation) is crucial for converting CTL exhaustion and can synergize with anti-PD1 treatment in rescuing exhausted CTLs in chronic infection. It will, thus, be interesting to exploit a potentially synergistic effect of CD40 agonist with the antagonistic treatment against other inhibitory molecules such as LAG-3, Tim-3, and TIGIT as a combination therapy in converting CTL exhaustion in chronic infection (Figure 2).

\section{Acknowledgment}

This study was supported by research funds from Canadian Institute of Health Research (PJT163314).

\section{Disclosure}

The authors report no conflicts of interest in this work.

\section{References}

1. Zhu Y, Yao S, Chen L. Cell surface signaling molecules in the control of immune responses: a tide model. Immunity. 2011;34(4):466-478.

2. Ahmed KA, Xie Y, Zhang X, Xiang J. Acquired pMHC I complexes greatly enhance CD4(+) Th cell's stimulatory effect on CD8(+) T cellmediated diabetes in transgenic RIP-mOVA mice. Cell Mol Immunol. 2008;5(6):407-415.

3. Ahmed KA, Xiang J. Mechanisms of cellular communication through intercellular protein transfer. J Cell Mol Med. 2011;15(7):1458-1473.

4. Ahmed KA, Xiang J. mTORC1 regulates mannose-6-phosphate receptor transport and T-cell vulnerability to regulatory $\mathrm{T}$ cells by controlling kinesin KIF13A. Cell Discov. 2017;3:17011.

5. Schluns KS, Lefrancois L. Cytokine control of memory T-cell development and survival. Nat Rev Immunol. 2003;3(4):269-279.

6. Quezada SA, Jarvinen LZ, Lind EF, Noelle RJ. CD40/CD154 interactions at the interface of tolerance and immunity. Annu Rev Immunol. 2004;22:307-328.

7. Vasilevko V, Ghochikyan A, Holterman MJ, Agadjanyan MG. CD80 (B7-1) and CD86 (B7-2) are functionally equivalent in the initiation and maintenance of CD4+ T-cell proliferation after activation with suboptimal doses of PHA. DNA Cell Biol. 2002;21(3):137-149.

8. Chen L. Co-inhibitory molecules of the B7-CD28 family in the control of T-cell immunity. Nat Rev Immunol. 2004;4(5):336-347.

9. Au PY, Yeh WC. Physiological roles and mechanisms of signaling by TRAF2 and TRAF5. Adv Exp Med Biol. 2007;597:32-47.

10. Stuber E, Strober W. The T cell-B cell interaction via OX40-OX40L is necessary for the T cell-dependent humoral immune response. $J$ Exp Med. 1996;183(3):979-989.

11. Futagawa T, Akiba H, Kodama T, et al. Expression and function of 4-1BB and 4-1BB ligand on murine dendritic cells. Int Immunol. 2002;14(3): 275-286.

12. Agematsu K, Kobata T, Sugita K, Hirose T, Schlossman SF, Morimoto C. Direct cellular communications between CD45R0 and CD45RA T cell subsets via CD27/CD70. J Immunol. 1995;154(8):3627-3635.

13. Schwartz JC, Zhang X, Nathenson SG, Almo SC. Structural mechanisms of costimulation. Nat Immunol. 2002;3(5):427-434. 
14. Paulie S, Rosen A, Ehlin-Henriksson B, et al. The human B lymphocyte and carcinoma antigen, $\mathrm{CDw} 40$, is a phosphoprotein involved in growth signal transduction. J Immunol. 1989;142(2):590-595.

15. Elgueta R, Benson MJ, de Vries VC, Wasiuk A, Guo Y, Noelle RJ. Molecular mechanism and function of CD40/CD40L engagement in the immune system. Immunol Rev. 2009;229(1):152-172.

16. Ahmed KA, Wang L, Munegowda MA, et al. Direct in vivo evidence of CD4+ T cell requirement for CTL response and memory via pMHC-I targeting and CD40L signaling. J Leukoc Biol. 2012;92(2):289-300.

17. Sun JC, Bevan MJ. Cutting edge: long-lived CD8 memory and protective immunity in the absence of CD40 expression on CD8 T cells. J Immunol. 2004;172(6):3385-3389.

18. Bourgeois C, Rocha B, Tanchot C. A role for CD40 expression on $\mathrm{CD} 8+\mathrm{T}$ cells in the generation of CD8+ T cell memory. Science. 2002;297(5589):2060-2063.

19. Ridge JP, Di Rosa F, Matzinger P. A conditioned dendritic cell can be a temporal bridge between a CD4+ T-helper and a T-killer cell. Nature. 1998;393(6684):474-478.

20. Tong AW, Stone MJ. Prospects for CD40-directed experimental therapy of human cancer. Cancer Gene Ther. 2003;10(1):1-13.

21. Ma DY, Clark EA. The role of CD40 and CD154/CD40L in dendritic cells. Semin Immunol. 2009;21(5):265-272.

22. Grewal IS, Xu J, Flavell RA. Impairment of antigen-specific T-cell priming in mice lacking CD40 ligand. Nature. 1995;378(6557):617-620.

23. O'Sullivan B, Thomas R. Recent advances on the role of CD40 and dendritic cells in immunity and tolerance. Curr Opin Hematol. 2003;10(4):272-278.

24. Prilliman KR, Lemmens EE, Palioungas G, et al. Cutting edge: a crucial role for B7-CD28 in transmitting Thelp from APC to CTL. J Immunol. 2002;169(8):4094-4097.

25. Ruedl C, Kopf M, Bachmann MF. CD8(+) T cells mediate CD40independent maturation of dendritic cells in vivo. $J$ Exp Med. 1999;189(12):1875-1884.

26. Lu Z, Yuan L, Zhou X, Sotomayor E, Levitsky HI, Pardoll DM. CD40independent pathways of $\mathrm{T}$ cell help for priming of CD8(+) cytotoxic T lymphocytes. J Exp Med. 2000;191(3):541-550.

27. Castellino F, Huang AY, Altan-Bonnet G, Stoll S, Scheinecker C, Germain RN. Chemokines enhance immunity by guiding naive CD8+ $\mathrm{T}$ cells to sites of CD4+ T cell-dendritic cell interaction. Nature. 2006;440(7086):890-895.

28. Johnson S, Zhan Y, Sutherland RM, et al. Selected Toll-like receptor ligands and viruses promote helper-independent cytotoxic $\mathrm{T}$ cell priming by upregulating CD40L on dendritic cells. Immunity. 2009;30(2):218-227.

29. Ahmed KA, Munegowda MA, Xie Y, Xiang J. Intercellular trogocytosis plays an important role in modulation of immune responses. Cell Mol Immunol. 2008;5(4):261-269.

30. Xiang J, Huang H, Liu Y. A new dynamic model of CD8+ T effector cell responses via CD4+ T helper-antigen-presenting cells. J Immunol. 2005;174(12):7497-7505.

31. He T, Tang C, Liu Y, et al. Bidirectional membrane molecule transfer between dendritic and T cells. Biochem Biophys Res Commun. 2007;359(2):202-208.

32. Hao S, Yuan J, Xiang J. Nonspecific CD4(+) T cells with uptake of antigen-specific dendritic cell-released exosomes stimulate antigenspecific CD8(+) CTL responses and long-term T cell memory. J Leukoc Biol. 2007;82(4):829-838.

33. He T, Zong S, Wu X, Wei Y, Xiang J. CD4+ T cell acquisition of the bystander pMHC I colocalizing in the same immunological synapse comprising pMHC II and costimulatory CD40, CD54, CD80, OX40L, and 41BBL. Biochem Biophys Res Commun. 2007;362(4):822-828.
34. Barinov A, Galgano A, Krenn G, Tanchot C, Vasseur F, Rocha B. CD4/CD8/Dendritic cell complexes in the spleen: CD8+ T cells can directly bind $\mathrm{CD} 4+\mathrm{T}$ cells and modulate their response. PLoS Oone. 2017;12(7): 0180644

35. Umeshappa CS, Xie Y, Xu S, et al. Th cells promote CTL survival and memory via acquired pMHC-I and endogenous IL-2 and CD40L signaling and by modulating apoptosis-controlling pathways. PLoS One. 2013;8(6):e64787.

36. Raker VK, Domogalla MP, Steinbrink K. Tolerogenic dendritic cells for regulatory T cell induction in man. Front Immunol. 2015;6:569.

37. Diehl L, den Boer AT, Schoenberger SP, et al. CD40 activation in vivo overcomes peptide-induced peripheral cytotoxic T-lymphocyte tolerance and augments anti-tumor vaccine efficacy. Nat Med. 1999;5(7):774-779.

38. Brossart P, Zobywalski A, Grunebach F, et al. Tumor necrosis factor alpha and CD40 ligand antagonize the inhibitory effects of interleukin 10 on T-cell stimulatory capacity of dendritic cells. Cancer Res. 2000;60(16):4485-4492.

39. Gurung P, Kucaba TA, Ferguson TA, Griffith TS. Activation-induced CD154 expression abrogates tolerance induced by apoptotic cells. J Immunol. 2009;183(10):6114-6123.

40. Higham EM, Wittrup KD, Chen J. Activation of tolerogenic dendritic cells in the tumor draining lymph nodes by CD8+ T cells engineered to express CD40 ligand. J Immunol. 2010;184(7):3394-3400.

41. Zhang X, Huang H, Yuan J, et al. CD4-8- dendritic cells prime CD4+ $\mathrm{T}$ regulatory 1 cells to suppress antitumor immunity. $J$ Immunol. 2005;175(5):2931-2937.

42. Zhang X, Kedl RM, Xiang J. CD40 ligation converts TGF-beta-secreting tolerogenic CD4-8- dendritic cells into IL-12-secreting immunogenic ones. Biochem Biophys Res Commun. 2009;379(4):954-958.

43. Barber DL, Wherry EJ, Masopust D, et al. Restoring function in exhausted CD8 T cells during chronic viral infection. Nature. 2006;439(7077):682-687.

44. Letvin NL, Walker BD. Immunopathogenesis and immunotherapy in AIDS virus infections. Nat Med. 2003;9(7):861-866.

45. Bhadra R, Gigley JP, Khan IA. Cutting edge: CD40-CD40 ligand pathway plays a critical CD8-intrinsic and -extrinsic role during rescue of exhausted CD8 T cells. J Immunol. 2011;187(9):4421-4425.

46. Isogawa M, Chung J, Murata Y, Kakimi K, Chisari FV. CD40 activation rescues antiviral CD8(+) T cells from PD-1-mediated exhaustion. PLoS Pathog. 2013;9(7):e1003490.

47. Xie Y, Wang L, Freywald A, Qureshi M, Chen Y, Xiang J. A novel T cell-based vaccine capable of stimulating long-term functional CTL memory against B16 melanoma via CD40L signaling. Cell Mol Immunol. 2013;10(1):72-77.

48. Wang R, Xu A, Zhang X, et al. Novel exosome-targeted T-cell-based vaccine counteracts T-cell anergy and converts CTL exhaustion in chronic infection via $\mathrm{CD} 40 \mathrm{~L}$ signaling through the mTORC1 pathway. Cell Mol Immunol. 2017;14(6):529-545.

49. Xu A, Wang R, Freywald A, et al. CD40 agonist converting CTL exhaustion via the activation of the mTORC1 pathway enhances PD-1 antagonist action in rescuing exhausted CTLs in chronic infection. Biochem Biophys Res Commun. 2017;484(3):662-667.

50. Ganeshan K, Chawla A. Metabolic regulation of immune responses. Annu Rev Immunol. 2014;32:609-634.

51. Pearce EL, Walsh MC, Cejas PJ, et al. Enhancing CD8 T-cell memory by modulating fatty acid metabolism. Nature. 2009;460(7251):103-107.

52. Anderson AC, Joller N, Kuchroo VK. Lag-3, Tim-3, and TIGIT: coinhibitory receptors with specialized functions in immune regulation. Immunity. 2016;44(5):989-1004.

53. Pauken KE, Wherry EJ. Overcoming T cell exhaustion in infection and cancer. Trends Immunol. 2015;36(4):265-276. 
ImmunoTargets and Therapy is an international, peer-reviewed open access journal focusing on the immunological basis of diseases, potential targets for immune based therapy and treatment protocols employed to improve patient management. Basic immunology and physiology of the immune system in health, and disease will be also covered. In addition, the journal will focus on the impact of manage- ment programs and new therapeutic agents and protocols on patient perspectives such as quality of life, adherence and satisfaction. The manuscript management system is completely online and includes a very quick and fair peer-review system, which is all easy to use. Visit http://www.dovepress.com/testimonials.php to read real quotes from published authors.

Submit your manuscript here: http://www.dovepress.com/immunotargets-and-therapy-journal 